\title{
Estado de recuperación del bosque nativo en una cuenca nordpatagónica de Chile, perturbada por grandes fuegos acaecidos 50 años atrás $\left(44^{\circ}-45^{\circ} \mathrm{S}\right)^{1}$
}

\author{
Víctor Quintanilla P.²
}

\begin{abstract}
RESUMEN
Los bosques nordpatagónicos de la región de Aisén en Chile meridional (44º $47^{\circ}$ sur) sufrieron grandes incendios entre 1936 y 1956, provocados por pioneros y ganaderos que despejaban la selva para habilitar praderas. La vegetación nativa se redujo aquí al $50 \%$ de la superficie original. Después de medio siglo de producidos estos impactos, los bosques han logrado mantener una cierta regeneración. Sin embargo, existen algunos sectores importantes donde esta recuperación es casi nula o muy dificultosa. Se inician los primeros estudios de un ejemplo de este tipo en una subcuenca andina patagónica.
\end{abstract}

Palabras clave: Fuegos, Nothofagus, estepa patagónica, regeneración, ecotono.

\begin{abstract}
Nordpatagonic forest of the Aisén region in meridional Chile $\left(44^{\circ} 47^{\prime}\right.$ south) has been affected by numerous large fires between the years 1936 to 1956 . They were produced by pioneers in their attempts to clear out lands for prairies. For that reason the native vegetation was reduced at $50 \%$ of the original covering. After a half of century of these impacts, the forest has reached a partial regeneration; however there are some important sectors where this regeneration is poor or null. We begin here the first study of this phenomenon in a Patagonic Andean sub-basinin.
\end{abstract}

Key words: Fires, Nothofagus, patagonic steppe, regeneration, ecotone.

Los bosques andino patagónicos chilenos, con toda su flora característica, forman parte de la Patagonia de Sudamérica, pero muy poca afinidad poseen con la vegetación de la Patagonia Semiárida muy extensa en territorio argentino, exceptuando una zona de ecotono bosque-estepa, y las ingresiones mutuas de estas formaciones debidas fundamentalmente al efecto de la actividades del Hombre. Todo un

1 Proyecto FONDECYT 1060115 "Estudio de los efectos de perturbaciones ambientales sobre la diversidad y dinamismo de los ecosistemas vegetales de Aisén continental. Cartografía fitoecológica". mosaico de agrupaciones vegetales es posible observar en dicho ecotono y dentro de la misma formación de estos bosques, a causa principalmente de la brusca disminución de las precipitaciones de oeste a este y en no más de $65 \mathrm{~km}$, que pueden variar desde los $4.000 \mathrm{~mm}$ anuales hasta menos de $600 \mathrm{~mm}$ (Oberdorfer, 1960). De esta manera, las especies se irán disponiendo de acuerdo a sus exigencias eco-

Artículo recibido el 5 de marzo de 2007 y aceptado el 17 de diciembre de 2007

2 Dpto. de Ingeniería Geográfica. Universidad de Santiago de Chile (USACH) (Chile). E-mail: vquintan@usach.cl 
lógicas, reuniéndose en armonía con el tipo de suelo, la humedad relativa, la intensidad de los vientos y todo otro factor limitante (Hueck, 1966; Dimitri, 1972).

Los más extensos e intensivos incendios de bosques registrados en Chile se produjeron en la región de los bosques patagónicos localizados en la denominada Región de Aisén $\left(44^{\circ}-47^{\circ} \mathrm{S}\right)$, entre los años 1936 y 1956, y consumieron alrededor de 3.000.000 de hectáreas (CONAF, 2006). Estos siniestros fueron parte de un proceso de habilitación de terrenos fiscales para ser ocupados por colonos. Con el tiempo se asentaron importantes sociedades ganaderas que ocuparon las mejores tierras estatales, lo que produjo que la ocupación de los colonos tuviera que hacerse en sectores de escasas praderas, para lo cual debían "limpiar" sus campos (bosques) y obtener así pastoreo para sus animales. Los fuegos no fueron solo por cuenta de los colonos; la industria maderera también se facilitaba el trabajo mediante incendios. Las quemas no controladas se efectuaron durante años. La mayor parte fue causada por estos pioneros, y los incendios se propagaban a veces un par de meses, en épocas estivales. A la llegada del invierno cesaban producto de las Iluvias, nevadas y escarchas (Grosse, 1979).
La pluviselva nordpatagónica fue penetrada en la parte continental de este territorio por grupos de colonos repatriados de Argentina que buscaban desarrollar una ganadería bovina y ovina, y para lo cual usaron frecuentemente la técnica del fuego para habilitar praderas. Hacia el sector de los fiordos, localizados al oeste de la región patagónica, predomina un bosque pluvial siempreverde donde destaca una importante conífera (Pilgerodendron uviferum (D.Don) Florin). En tanto en la parte central continental existe un dominio de bosques húmedos deciduos, principalmente con Nothofagus; y luego hacia el este se contactan con las comunidades estepáricas típicas de la Patagonia. En esta transecta biogeográfica de oeste a este se distribuye una interesante fauna de aves y mamíferos (Figura $N^{\circ} 1$ ).

Estos bosques nordptagónicos principalmente están constituidos por Nothofagus pumilio (Poepp. et Endel.) Krasser (lenga), N. dombeyi (Mirbel) Oersted (coigüe común), N. antarctica (G. Forster) Oersted y N. betuloides (Mirbel) Oersted (coigüe de Magallanes), que ocupan una importante superficie de la Región de Aisén, en un rango altitudinal que fluctúa aproximadamente entre los 200 y 800 m.s.n.m.

Figura $\mathrm{N}^{\mathrm{o}} 1$

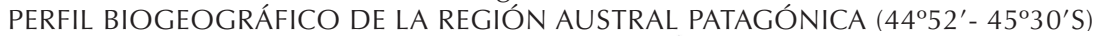

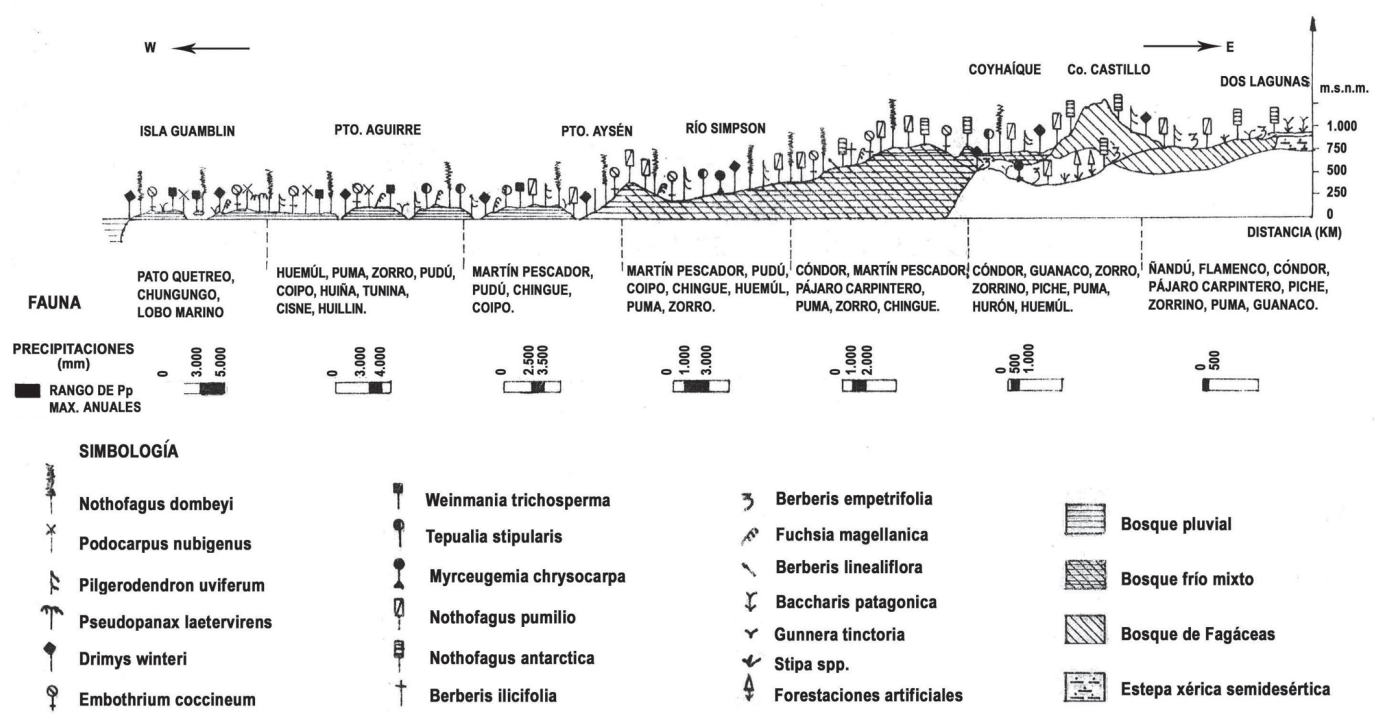

Fuente: Quintanilla (1989). 
El bosque de lenga es el tipo forestal más abundante en este territorio, ello responde a una gran adaptación a variadas condiciones de precipitaciones y sustrato (Armesto et al., 1992; Armesto et al., 1995). Sin embargo, lo que es común a toda la distribución de la especie, es su presencia en suelos delgados y de texturas gruesas y en climas donde, por altitud o por latitud, la nieve es la forma de precipitación dominante, con temperaturas normalmente bajas (Armesto et al., 1992). Este bosque deciduo constituye el límite altitudinal de la vegetación arbórea de toda la región andino patagónica, desplazándose en esta área entre los 500 y 800 m.s.n.m. (Quintanilla, 1983). La mayor parte de las superficies forestales incendiadas en Aisén se encuentran en relieves muy accidentados lo que ha implicado que muchos terrenos desarbolados estén sufriendo procesos erosivos permanentes. En Coihaique Nothofagus pumilio suele encontrársele hasta los 700 m.s.n.m. (Donoso et al., 2004).

Por otra parte, la industria maderera de la Región de Aisén está basada fundamentalmente en la lenga, ocupando sobre un $50 \%$ de la producción anual $\left(1.171 .240 \mathrm{~m}^{3}\right) \mathrm{se}-$ guida por el coigüe (Donoso, 1998). Esta alta incidencia se debe a diversas ventajas comparativas que posee Nothofagus pumilio (lenga) sobre otras especies, ya sea en la resistencia para todo tipo de construcciones; mayor accesibilidad de los rodales productivos a los centros de comercialización, debido a su ubicación en sectores que cuentan con la mayor parte de la infraestructura caminera de la región; y finalmente que existe una importante demanda en el mercado exterior por esta madera. Debe señalarse por lo demás, que este Nothofagus se distribuye en las montañas de Chile desde los $35^{\circ}$ latitud sur hasta Tierra del Fuego.

El afán de los colonizadores por formar praderas, eliminado la vegetación arbórea a través de las quemas, trajo como consecuencias, en gran parte de los casos, incendios de gran magnitud, agudizados principalmente por la acción de los fuertes vientos que caracterizan la región. Como resultado de estos hechos extensas superficies de aptitud o uso fundamentalmente forestal quedan con el suelo desnudo o bien cubierto solo con pastizales y malezas, que hoy sustentan la ganadería de Aisén. Cabe señalar que esta situación no se repitió con tanta intensidad en la zona occidental de los bosques de fiordos, debido básicamente a factores climáticos (alta pluviometría), morfológicos a la difícil accesibilidad y ausencia de colonización.

Como consecuencia del avance de los colonos y el aumento demográfico consiguiente se inició la explotación de los extensos bosques de lenga que en aquel entonces cubrían la mayor parte de la zona central y oriental de la región. Los pobladores necesitaban madera para sus viviendas, galpones y otras construcciones, requeridas para implementar una infraestructura básica en los grandes predios. A fin de satisfacer las necesidades regionales, incrementada además, entonces, con la demanda de la república Argentina, se inició una intensiva y extensa explotación de los bosques de lenga.

Hoy día, después de 50 años de estas grandes perturbaciones, se hacen intentos (algunos exitosos) por recuperar la primitiva masa arbórea con forestaciones de la misma lenga, pero sobre todo, con coníferas extranjeras: (Pinus ponderosa Dougl. Ex Laws, Pinus contorta var. latifolia, Pseudotsuga menziessii (Mirb.) Franco o pino oregón; entre las más utilizadas.

\section{Área de estudio}

\section{Breves antecedentes biofísicos}

La unidad de trabajo se localiza entre los $45^{\circ} 19^{\prime}-45^{\circ} 23^{\prime}$ latitud sur y $71^{\circ} 45^{\prime}$ $71^{\circ} 51^{\prime}$ longitud oeste, distante a $45 \mathrm{~km}$ al noreste de la ciudad de Coihaique, capital administrativa de la Región de Aisén (Figura $\mathrm{N}^{\circ} 2$ ).

El clima dominante es el tipo trasandino con degeneración estepárica o clima semiárido patagónico según la clasificación de Koeppen (IREN-CORFO, 1979), que se caracteriza por tener suficientes precipitaciones durante casi todos los meses del año (nieve en invierno) y oscilaciones térmicas anual y diarias acentuadas. Se representan a continuación los datos meteorológicos correspondientes a las ciudades de Puerto Aisén (10 m.s.n.m.) y Coihaique (343 
Figura $\mathrm{N}^{\circ} 2$

APROXIMACIÓN AL ÁREA DE ESTUDIO: XI REGIÓN DE AISÉN

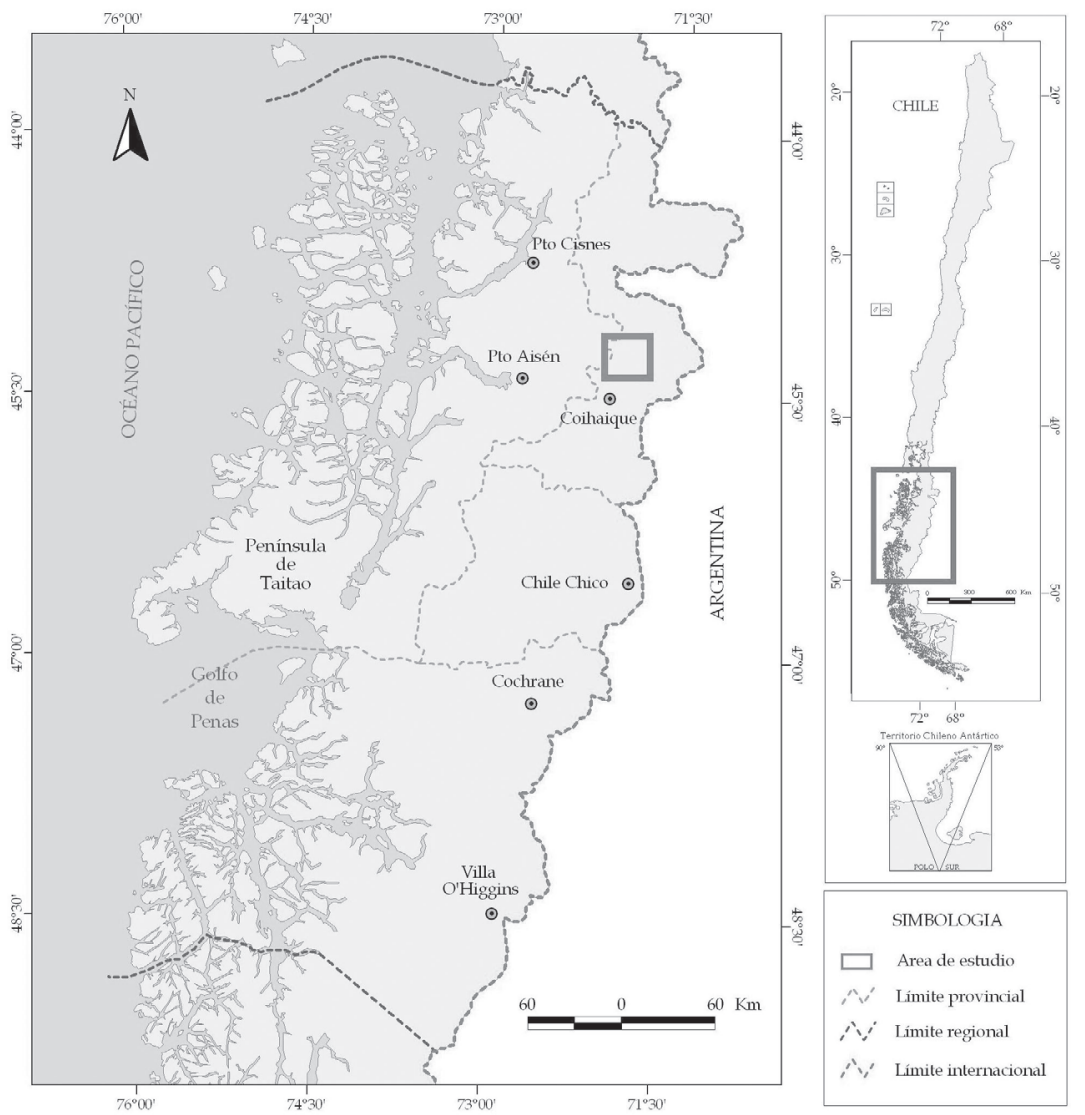

Fuente: Elaboración propia.

m.s.n.m.); esta última situada en el área próxima al ecotono entre el bosque y la estepa en esta región austral (Figuras $\mathrm{N}^{\circ} 3 \mathrm{y}$ $N^{0}$ 4). Puerto Aisén, en 23 años de observaciones, presenta un promedio precipitaciones del orden de los $2.941 \mathrm{~mm}$; en tanto que Coihaique de $835 \mathrm{~mm}$. A su vez, para el mismo período de observaciones, el promedio de humedad de Puerto Aisén alcanzaría el $81,9 \%$, y para Coihaique el $74,6 \%$ (DGA-MOP, 2007).

Los vientos en toda esta región circulan predominantemente desde el sur, durante todo el año, con un aumento de su intensidad y a veces de las temperaturas en los meses de verano. Otro factor meteorológico es la nubosidad; en promedio 214 días al año cubiertos (DGA-MOP, 2007).
El relieve del área de estudio en general presenta una morfología accidentada, con valles ondulados, en algunos de los cuales se destacan testimonios de actividad volcánica y también presencia de terrazas fluvio-glaciales. Las mayores altitudes corresponderían a cordones morrénicos y a modestos macizos con fisonomía casi de lomas, las cuales no superan los $1.450 \mathrm{~m}$ de altitud. El fondo de valle se sitúa aproximadamente entre los 700 y 860 m.s.n.m., y se encuentra surcado por el curso medio del río o estero Richards, correspondiente a una de las tantas subcuencas patagónicas del diversificado drenaje de la región, varias de las cuales reciben agua de numerosas y pequeñas lagunas glaciales. El río nace de sur a norte y luego dirige su curso hacia el este, descendiendo hacia la estepa patagónica (Figura № 5). 
Figura $\mathrm{N}^{0} 3$

DIAGRAMAS OMBROTÉRMICOS DE PUERTO AISÉN Y COIHAIQUE
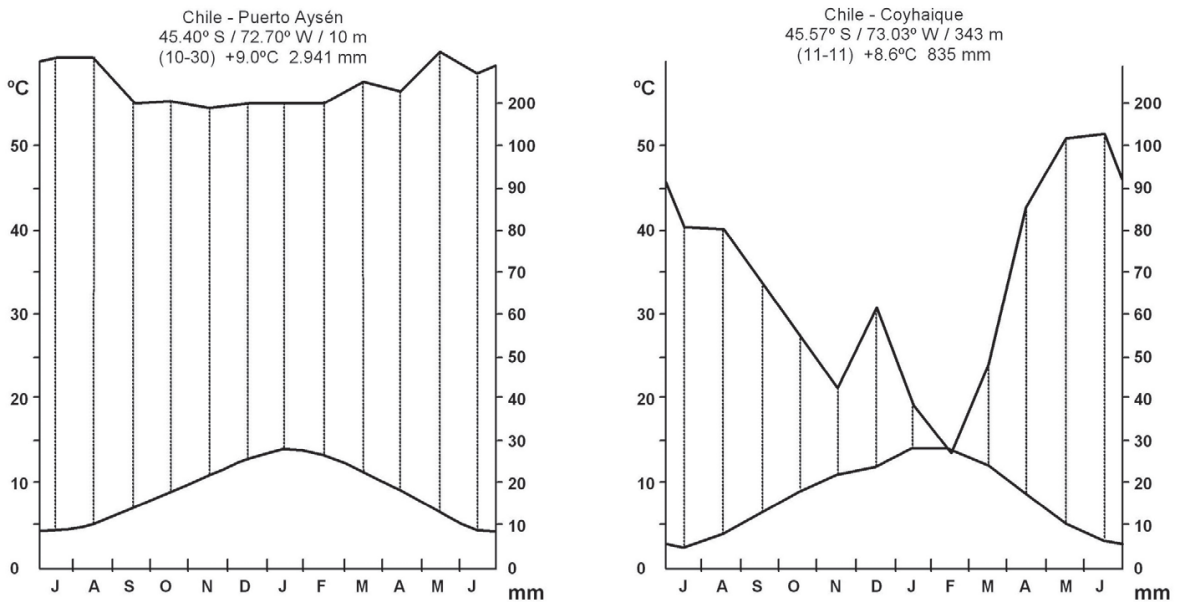

Fuente: INIA (1989); DGA-MOP (2007).

Figura $\mathrm{N}^{\circ} 4$

ECOTONO ENTRE EL BOSQUE DE NOTHOFAGUS Y LA ESTEPA PATAGÓNICA

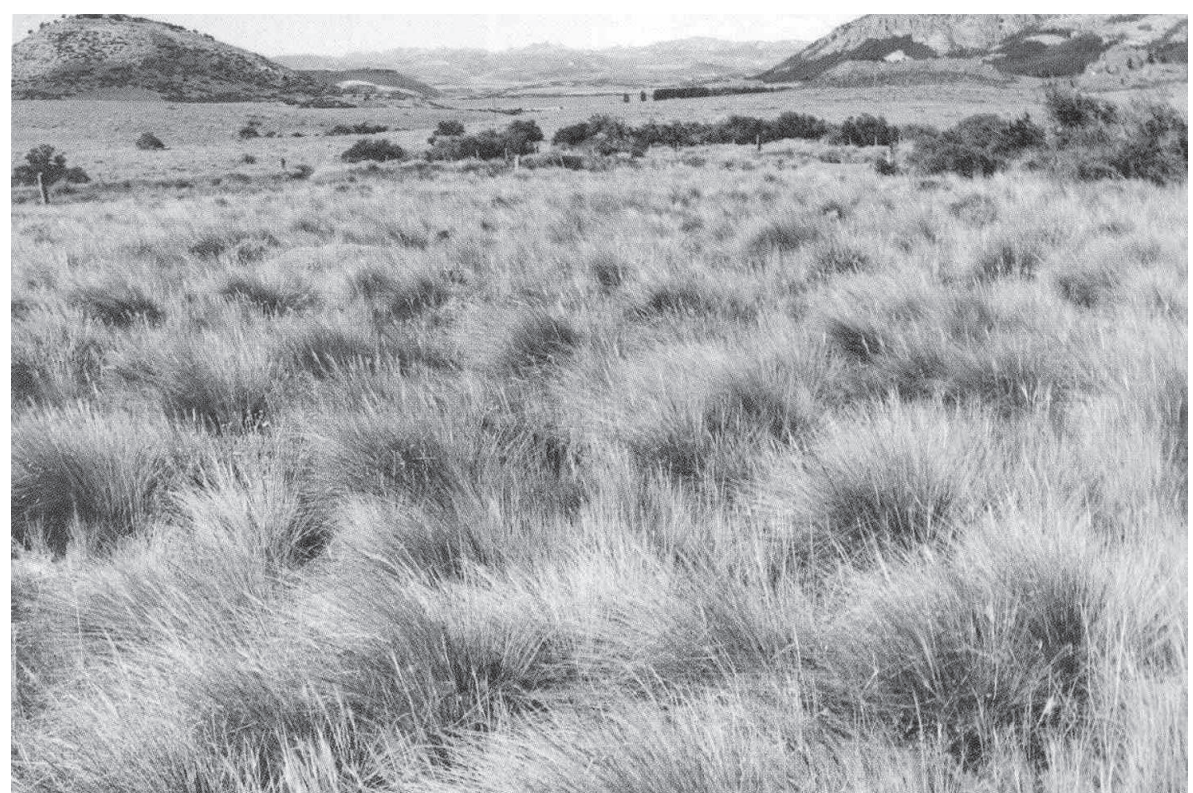

Fuente: Colección personal del autor. 
Figura $N^{\circ} 5$

ÁREA DE ESTUDIO

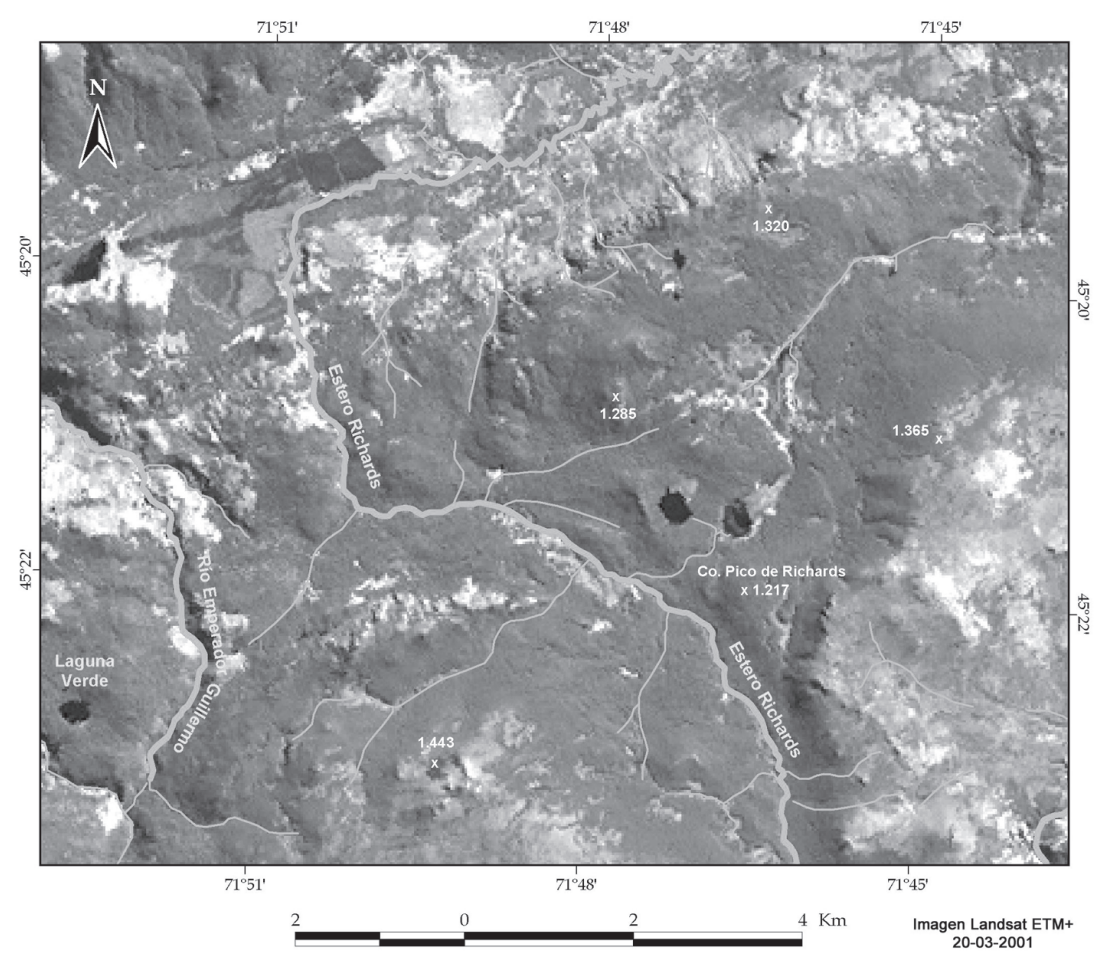

Fuente: Elaboración propia.

Desde el punto de vista geológico destacan unidades metamórficas, dioritas del triásico y complejo granítico del cretácico (Borgel, 1982). En los sectores más elevados existen abundantes detritos gruesos y escasa meteorización, en tanto en el sector del lecho del Estero Richards se presentan sedimentos fluviales y glaciales.

Los suelos corresponden al denominado tipo forestal lenga, el cual crece sobre un sustrato profundo de origen volcánico (Wrigth, 1967: citado por Mascareño, 1987). La textura es liviana, franco limosa o franco-arenosa fina, donde predominan los colores café rojizos, siendo extremadamente susceptibles a la erosión eólica pluvial. En general ellos tienen un buen drenaje, con excepción de las áreas de "mallines" (Veblen et al., 1979). A su vez Mascareño (1987) y Roig (1998) señalan que la podzolización es el proceso formador de suelos dominantes en los bosques de lenga. En los sectores altos, el suelo se ha desarrollado sobre rocas ígneas, sedimentarias, metamórficas y algunas intrusivas; y en los sectores bajos el material volcánico se depositó sobre conos de deyección, morrenas, planos aluviales y fluvioglaciales. El horizonte superficial suele ser de textura arenosa a franco arenosa, pero bajo esta se presentan arenas fluvioglaciales, guijarros y roca fragmentada; todo lo cual aflora en la superficie en laderas expuestas a erosión. (IREN-CORFO, 1979; SAG, 1999a).

Se conoce en Chile como "mallín" a una formación natural caracterizada por suelos de baja permeabilidad que determinan anegamientos invernales, favoreciendo el crecimiento de musgos, juncos, helechos y ciertas especies de árboles y/o arbustos (ej. Amomyrtus luma, Drimys winteri, Pilgerodendron uviferum, Nothofagus antarctica). Para Roig (1998) serían, particularmente en Argentina, praderas de gramíneas, juncáceas 
y ciperáceas en suelos húmedos. El término es de origen mapuche que significa lugar bajo y anegadizo.

Debido a que actualmente la vegetación predominante en nuestra área de estudio corresponde a un bosque abierto y bajo de lenga, en muy lenta regeneración; los sectores de erosión son notorios, lo cual también se observa en otras áreas de la Región de Aisén. De igual modo se manifiesta una moderada erosión causada por la nieve.

\section{Materiales y métodos}

El área de estudio fue delimitada en cartas topográficas de escala 1:50.000 del Instituto Geográfico Militar, y analizada con el apoyo y uso de sensores remotos. Se fotointerpretó clichés pancromáticos de escala 1: 60.000 (año 1961), y se analizó una imagen Landsat Thematic Mapper, del 20 marzo de 2001. Con estos sensores se localizaron coberturas territoriales (orografía, red de drenaje, cuerpos de agua); sectores de antiguos incendios; presencia actual de áreas con renovales y plantaciones exóticas, además lugares de suelos desnudos en la subcuenca superior del río Richards. El área estudiada tiene una superficie aproximada de 30 ha, y se observó en la imagen la estructura del bosque y sus sectores de contacto con la estepa patagónica.
En este trabajo de gabinete se compararon las diferentes cartas temáticas de vegetación para América del Sur y la Patagonia y otros estudios a nuestro alcance: Soriano (1956); Hueck (1966); Cabrera y Willink (1973); UNESCO (1973); Cabrera (1976); Pisano (1977); Quintanilla (1989); Castellanos y Pérez-Moreau (1944); y Roig (1998).

Se llevó a cabo una campaña de trabajo de campo en la segunda semana de enero de 2007, efectuando 12 censos fitosociológicos, siguiendo y simplificando la metodología de Braun-Blanquet (1979), consideraron solo las especies leñosas. La superficie de las parcelas establecidas abarcó $60 \mathrm{~m}^{2}$ cada una; tanto en sectores de laderas como en fondo de valles.

\section{Resultados y discusión}

El estudio se desarrolló en un bosque de renuevo disperso con árboles de baja talla, ubicados en áreas quemadas medio siglo atrás, cuya edad no sobrepasaría el decenio; y se constató la penetración de especies de la estepa patagónica. El análisis de los censos nos llevó a determinar una primera identificación y clasificación de las especies más constantes en la estación de verano, localizando la topografía de su hábitat. Interesante resultó constatar la notoria presencia de plantas exóticas (Cuadro $\mathrm{N}^{\circ} 1$ ).

Cuadro $\mathrm{N}^{\circ} 1$

SÍNTESIS DE LOS INVENTARIOS FLORÍSTICOS (ENERO 2007)

\begin{tabular}{|c|c|c|c|c|c|}
\hline Nombre científico & Nombre vulgar & Familia & Origen & $\begin{array}{c}\text { Sector } \\
\text { Recolecta }\end{array}$ & Forma \\
\hline Acaena ovalifolia & cadillo & Rosaceae & Nativa & $\begin{array}{l}\text { Bajos - } \\
\text { laderas }\end{array}$ & Hierba \\
\hline Adenocaulon chilense & adenocaulon & Compuesta & Nativa & $\begin{array}{l}\text { Altura - } \\
\text { mallín }\end{array}$ & Hierba \\
\hline Agrostis capillaris & chépica & Gramineae & Eurasia & $\begin{array}{l}\text { Altura - } \\
\text { mallín }\end{array}$ & Hierba \\
\hline Baccharis avobata & vautro & Astevaceae & Nativa & $\begin{array}{l}\text { Altura - } \\
\text { mallín }\end{array}$ & Arbusto \\
\hline Betula pendula & abedul & Betulaceae & Eurasia & Ladera & Árbol \\
\hline Berberis buxifolia & calafate & Berbidaceae & Nativa & Ladera & Arbusto \\
\hline
\end{tabular}


Cuadro $\mathrm{N}^{\circ} 1$

(CONTINUACIÓN)

\begin{tabular}{|c|c|c|c|c|c|}
\hline $\begin{array}{l}\text { Blechnum penna- } \\
\text { marina }\end{array}$ & pinque & Polipodiaceae & Nativa & $\begin{array}{l}\text { Bajos - } \\
\text { ladera }\end{array}$ & Helecho \\
\hline Cerastium arvense & correhuela & Carofilaceae & Eurasia & $\begin{array}{l}\text { Bajos - } \\
\text { mallín }\end{array}$ & Hierba \\
\hline Codornichis lessoni & azucena & Orquidaceae & Nativa & Ladera & Hierba \\
\hline Cyrsium vulgare & cardo & Compositae & Canadá & Ladera & Arbusto \\
\hline Cytisus scoparius & $\begin{array}{l}\text { retamo de } \\
\text { escobas }\end{array}$ & Papilionaceae & Europa & $\begin{array}{l}\text { Ladera - } \\
\text { pradera }\end{array}$ & Hierba \\
\hline Chiliotrichium diffusum & mata verde & Compuestas & Nativa & Bosque & Arbusto \\
\hline Chusquea macrostachya & taihuén & Gramineae & Nativa & Bajos & Arbusto \\
\hline Dactylis glomerata & pasto ovillo & Gramineae & Europa & Ladera & Hierba \\
\hline Desfontainia spinosa & taique & Desfontainiáceae & Nativa & $\begin{array}{l}\text { Bajos - } \\
\text { ladera }\end{array}$ & Árbol \\
\hline Embothrium coccineum & notro & Proteaceae & Nativa & $\begin{array}{l}\text { Bajos - } \\
\text { ladera }\end{array}$ & Árbol \\
\hline Empetrum rubrum & uvilla & Empetraceae & Nativa & $\begin{array}{l}\text { Altura - } \\
\text { mallín }\end{array}$ & Arbusto \\
\hline Epilobium ciliatum & epilobio & Onagraceae & Nativa & Bajos & Hierba \\
\hline Fragaria chiloensis & frutilla & Rosaceae & Nativa & Bajos & Arbusto \\
\hline Gamochaeta spiciforme & gnafalium & Compuesta & Nativa & Ladera & Hierba \\
\hline Geranium patagonicum & core-core & Geriniaceae & Nativa & Bajos & Hierba \\
\hline Hypericum perforatum & alfalfa argentina & Hypericaceae & Nativa & Bajos & Arbusto \\
\hline Hypochoeris arenaria & $\begin{array}{l}\text { hierba del } \\
\text { chancho }\end{array}$ & Compuesta & Eurasia & $\begin{array}{l}\text { Bajos - } \\
\text { ladera }\end{array}$ & Hierba \\
\hline Juncus bufonis & junquillo & Juncaceae & S. África & Tallin & Hierba \\
\hline Juncos proserus & junco & Juncaceae & S. África & Tallin & Hierba \\
\hline Maytenus disticha & maitén chico & Celasteraceae & Nativa & Sotobosque & Arbusto \\
\hline Nassauvia revoluta & masauvia & Compuesta & S. África & Altura & hierba \\
\hline Nothofagus pumilio & lenga & Fagaceae & Nativa & $\begin{array}{l}\text { Altura - } \\
\text { ladera }\end{array}$ & Árbol \\
\hline Osmorhiza chilensis & $\begin{array}{l}\text { perejil de } \\
\text { bosque }\end{array}$ & Umbeliferaceae & Nativa & $\begin{array}{l}\text { Ladera - } \\
\text { mallín }\end{array}$ & Hierba \\
\hline Ovidia andina & pillo-pillo & Timeleaceae & Nativa & $\begin{array}{l}\text { Altura - } \\
\text { pradera }\end{array}$ & Arbusto \\
\hline Pernettya mucronata & chaura & Ericaceae & Nativa & $\begin{array}{l}\text { Altura - } \\
\text { mallín }\end{array}$ & Arbusto \\
\hline $\begin{array}{l}\text { Perezia } \\
\text { pediculariadifolia }\end{array}$ & $\begin{array}{l}\text { estrella de } \\
\text { los andes }\end{array}$ & Compuesta & Nativa & $\begin{array}{l}\text { Altura - } \\
\text { ladera }\end{array}$ & Hierba \\
\hline Pinus contorta & pino contorta & Pinaceae & N. América & Ladera & Árbol \\
\hline Plantago lanceolata & Ilantén & Plantaginaceae & Europa & $\begin{array}{l}\text { Bajos - } \\
\text { ladera }\end{array}$ & Hierba \\
\hline Poa pratensis & pasto azul & Plantaginaceae & Europa & $\begin{array}{l}\text { Bajos - } \\
\text { ladera }\end{array}$ & Hierba \\
\hline
\end{tabular}


Cuadro $\mathrm{N}^{\circ} 1$

(CONTINUACIÓN)

\begin{tabular}{|c|c|c|c|c|c|}
\hline Prunella vulgaris & hierba mora & Lamiaceae & Europa & Bajos & Hierba \\
\hline Ranunculus peduncularis & ranunculo & Ranculaceae & Nativa & Bajos & Hierba \\
\hline Ribes magellanicum & zarzaparrilla & Grosulariaceae & Nativa & $\begin{array}{l}\text { Ladera - } \\
\text { mallín }\end{array}$ & Arbusto \\
\hline Rumex acetosella & vinagrillo & Poligonaceae & Eurasia & $\begin{array}{l}\text { Altura - } \\
\text { ladera }\end{array}$ & Hierba \\
\hline Sambucus nigra & sauco europeo & Cuprifoliaceae & Exotica & Bajos & Arbusto \\
\hline Schinus patagonicus & huingan & Anacardiaceae & Nativa & Pradera & Arbusto \\
\hline Senecio vulgaris & senecio & Compuesta & Europa & Altura & Hierba \\
\hline Taraxacum officinale & diente de leon & Compuesta & Eurasia & Bajos & Hierba \\
\hline
\end{tabular}

Fuente: Elaboración propia.

Teniendo en consideración que el último incendio devastador en esta área sucedió en el verano de 1952; actualmente se observa que la mayoría de la escasa masa forestal está compuesta por árboles de renuevo y con algunos escasos individuos invasores de Rosa rubiginosa.

Las fuentes señalan que el bosque original predominante aquí estaba compuesto en su mayor parte por Nothofagus pumilio acompañado hacia la línea del timberline por Nothofagus antarctica. Ambas Nothofagáceas constituyen el componente principal de las formaciones boscosas que varios autores denominan como los Bosques Caducifolios Subantárticos de Sudamérica (Schmithüsen, 1956; Oberdorfer, 1960; Pisano, 1965; Di Castri, 1968; Veblen et al., 1979). Considerando alguno de sus caracteres ecológicos, autores chilenos y argentinos tipifican estas agrupaciones con denominaciones como: Bosques Andinos Patagónicos (Dimitri, 1972); Bosque deciduo frío con dominancia de Nothofagus pumilio (Quintanilla, 1989); Bosque Caducifolio de Aisén (Gajardo, 1994) o Bosque mesófilo de Nothofagus pumilio (Roig, 1998). Por último, Donoso (1998) subdivide el tipo forestal lenga en bosques achaparrados y krummholz de lenga, bosque de lenga puro, y bosque mixto de lenga y coigüe común (Nothofagus dombeyi).
Es indudable que de acuerdo a su distribución latitudinal y altitudinal estos bosques orófilos de lenga, sobre todo en Chile, pueden variar su estructura y densidad conforme aumentan las precipitaciones, y si estas a su vez son mayormente líquidas o nivosas.

En nuestra área de estudio, este joven bosque presenta dos estadios: un subpiso del bosque propiamente tal y abierto, y el de lenga achaparrada (krummholz). Este último formado por matorrales de 1-3 m de alto, ocupa la parte superior en contacto con la escasa vegetación altoandina, y puede conformar un cinturón de 50 a 200 m, que sufre en gran medida el efecto del peso físico mecánico de los rodados e incluso de la nieve, cumpliendo por los demás un rol de amortiguador de las avalanchas. Situación similar señala Roig (1998) para estos bosques en los Andes argentinos de la provincia de Chubut (Figura $N^{\circ} 6$ ).

La colecta e identificación de plantas se concentraron en dos áreas según el gradiente altitudinal: el borde de estepa-pastizal y en el bosque de renuevo. La identificación se realizó también con colectas que se analizaron en los laboratorios regionales de la CONAF y del SAG de la ciudad de Coihaique. De la síntesis de la docena de censos levantados, discriminamos los tipos de formas vegetales presentes según se indica en el Cuadro $\mathrm{N}^{\circ} 2$. 
Figura $\mathrm{N}^{\circ} 6$

TRANSECTA VEGETAL EN LA CUENCA DEL ESTERO RICHARD

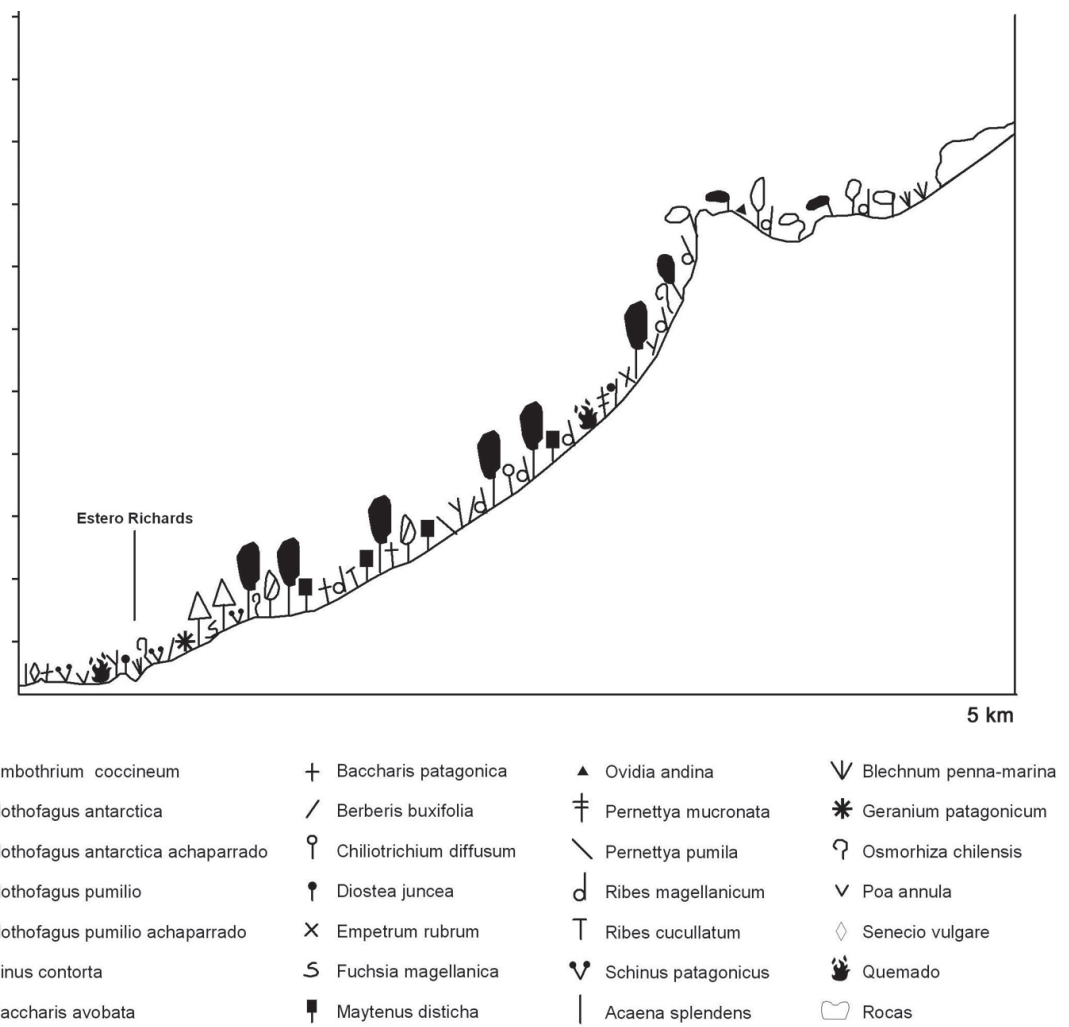

Fuente: Elaboración propia.

Cuadro $\mathrm{N}^{\circ} 2$

NÚMERO DE PLANTAS COLECTADAS

\begin{tabular}{|l|c|c|c|}
\hline Estrato vegetal & Nativas & Exóticas & TOTAL \\
\hline Árboles & 3 & 2 & 5 \\
Arbustos & 13 & 3 & 16 \\
Herbáceas & 17 & 13 & 30 \\
TOTAL & 33 & 18 & 51 \\
PORCENTAJE & 64,7 & 35,2 & 100 \\
\hline
\end{tabular}

Fuente: Elaboración propia.

Dado que este total de especies está distribuido en dos ambientes fitoecológicos es posible afirmar que la vegetación de esta área sería relativamente simple y de baja diversidad. Por otra parte, la aparición de 18 espe- cies exóticas encontradas en este verano determina el testimonio de una acción antrópica importante; la cual se va acentuando más hacia el sur del continente sudamericano, inclusive en Tierra del Fuego (Brion et al., 1988). 
Reconocido que el árbol dominante en este alterado bosque nativo es Nothofagus pumilio (la lenga), se encuentra ubicado en un mosaico entre la estepa patagónica hacia el este y el bosque siempreverde hacia las costas de fiordos (Oeste). Recordamos que aquí los gradientes climático-físicos de mayor relevancia para la distribución de las comunidades autóctonas son la precipitación y la altitud.

La comunidad más representativa correspondería a la constituida por la asociación de Nothofagus pumilio-Ribes magellanicum Poir, que se encuentra preferentemente en los pisos superiores de la cordillera, y que en el extremo altitudinal se caracteriza por la fisonomía de lengas achaparradas. Las especies en relación a su porcentaje de presencia se indican en la Cuadro $\mathrm{N}^{\circ} 3$.

Es interesante destacar que Schinus patagonicus (laura) posee una baja representación, en circunstancias que en otras áreas biogeográficas de Aisén tiene una presencia importante en los sectores de transición entre el bosque subantártico y la estepa patagónica. Igual fenómeno observamos con respecto a Chusquea coleu E. Desv. (caña, coligüe), gramínea habitante algo común en sectores andino-patagónicos.

La lenga forma en general bosques puros, pero en lugares de contacto con otros grupos forestales suele mezclarse con $\mathrm{N}$. dombeyi, N. betuloides o con Drimys winteri, especialmente en sitios más húmedos y de menor altitud (Donoso et al., 2004). Aquí lo hemos encontrado como un bosque de renuevos de unos 10 metros de alto, el cual fisionómicamente se observa con árboles medianos. En su estrato arbustivo en tanto, predominan especies de hojas coriáceas y xeromórficas, tales como Berberis buxifolia, Maytenus disticha, Pernettya mucronata, y muy escasa (a diferencia de otras áreas) la Rosa rubiginosa. Es notoria la colonización en laderas por Embothrium coccineum cuyos arbolitos de renuevo están en los espacios que antes de los fuegos, ocupaban los Nothofagus y en particular el coigüe. El notro es pionero en los terrenos abiertos y en los suelos volcánicos ricos en materia orgánica.

Se confirma lo mencionado por Veblen et al. (1982), que al interior del estrato arbustivo, como antes señalamos, se encuentra ausente el género Chusquea, en contraste con lo que se observa en los bosques vecinos siempreverdes; y en su lugar existe una formación herbácea con mejor desarrollo.

Hemos identificado en gran parte del área, tanto en laderas como en fondo de valle, un bosque poco estratificado, sin lianas y epífitas, lo cual podría deberse al duradero impacto de los fuegos reiterados y la frecuencia de vientos intensos. Existe eso sí un piso de musgos que puede llegar a desapa-

Cuadro $\mathrm{N}^{\circ} 3$

ESPECIES PRESENTES EN LA ASOCIACIÓN N. PUMILIO-RIBES MAGELLANICUM (SIN.R.BUXIFOLIA)

\begin{tabular}{|l|l|c|}
\hline $\begin{array}{c}\text { Especies representativas } \\
\text { (presencia 75-100\%) }\end{array}$ & $\begin{array}{c}\text { Especies comunes } \\
\text { (presencia 50-75\%) }\end{array}$ & $\begin{array}{c}\text { Especies acompañantes } \\
\text { (presencia 25-50\%) }\end{array}$ \\
\hline \multirow{2}{*}{ Nothofagus pumilio } & Osmorhiza chilensis & \multirow{2}{*}{ Adenocaulum chilense } \\
\cline { 2 - 2 } & Ribes cucullatum & \multirow{2}{*}{ Embothrium coccineum } \\
\cline { 2 - 2 } & Chiliotrichium diffusum & \multirow{2}{*}{ Maytenus disticha } \\
\hline \multirow{2}{*}{ Ribes magellanicum } & Berberis buxifolia & \\
\cline { 2 - 2 } & Empetrum rubrum & \\
\cline { 2 - 3 } & Pernettya mucronata & \\
\hline
\end{tabular}

Fuente: Elaboración propia. 
recer en los bosques más densos. El piso herbáceo posee una alta representatividad de hierbas y gramíneas, sobre todo en los sectores próximos al contacto con la estepa.

Por otra parte, la lenga en este sector no presenta una alta regeneración natural, situación que es más común en los bosques nordpatagónicos argentinos, aún afectados por el fuego, produciendo semillas cada 3 ó 4 años alternando con otros de baja producción (Roig, 1998). Es una especie relativamente longeva por cuanto estudios hechos por autores en rodales de otros sectores de Aisén, establecieron que la edad media de ellos, era entre 144 y 149 años, aunque existirían ejemplares de hasta 300 años (Alfaro, 1982). Las raíces son gruesas y subsuperficiales, concentrándose en los primeros 40-50 cm del perfil, lo que origina una plataforma de apoyo al árbol dentro de la masa, pero no le otorga suficiente seguridad ante las ráfagas del viento cuando está aislado o con poca protección. También se constata de acuerdo con informes del SAG (1999), que en estas áreas los mallines y fachinales son escasos.

Los suelos ácidos y de baja saturación de bases acarrean problemas nutritivos que la lenga soluciona asociándose con hongos simbiontes, por ejemplo de los géneros Russula, Tricholoma, con los cuales forma micorrizas en sus raíces finas y poniendo a su alcance los nutrientes críticos como el N, K o P (Alfaro, 1982; Roig, 1998).

Características de la recuperación postfuego del bosque de Nothofagus pumilio en el área de estudio

Los grandes incendios forestales acaecidos en la Región de Aisén hasta cincuenta años atrás, abarcaron gran parte de la hoya hidrográfica del río homónimo donde se ubica la pequeña subcuenca del denominado estero Richards, en área de contacto con la estepa patagónica.

Como en otras partes del mundo en general, los efectos de los incendios varían de acuerdo con las magnitudes sumadas de intensidad y duración. Los grandes fuegos en Aisén se caracterizaron porque fundamentalmente consumieron combustibles verdes pesados, que desarrollaron altas temperaturas con grandes tiempos de permanencia en el lugar. Los últimos siniestros de gran extensión ocurrieron en esta región en la temporada de verano de 1997/1998 cuando ardieron alrededor de 25.000 ha en el sector de Lago Verde. Es conocido que el calor emanado por los incendios tiene un efecto de esterilización temporal que puede mejorar el crecimiento de las plantas nativas, a menudo a un año de producido el evento fenómeno que acá, según las fuentes orales, no habría sucedido. La pérdida del bosque por los fuegos reiterados en el relieve montañoso desarticuló a menudo la regeneración. Solo en ciertos trechos del fondo de valle y próximos al curso principal de agua prospera una lenta regeneración arbórea ( $\mathrm{Fi}$ gura $\mathrm{N}^{\circ} 7$ ). A su vez, el desmantelamiento del bosque en fuertes pendientes, contribuyó a un desencadenamiento de rodados y deslizamientos bastante frecuentes. Para frenar o reducir los efectos de estos procesos, se foresta en laderas con Pinus ponderosa y $P$. contorta (Figura $\mathrm{N}^{\circ} 8$ ).

La constante y fuerte circulación de los vientos en esta región, además de provocar alteraciones al crecimiento arbóreo, fue el principal agente de la expansión de estos fuegos estivales, que incluso alcanzaron a territorio argentino en varias ocasiones. Los bosques puros de lenga (Nothofagus pumilio) y coigüe de Magallanes ( $N$. betuloides) son muy sensibles al fuego, y crecen en competencia en extensas áreas con pastizales de Stipa, Festuca y Poa, los cuales forman los denominados "coironales" en esta región de Chile.

Autores como Armesto et al. (1992); Veblen et al. (1995); Donoso (1998); Roig (1998); Quintanilla (2005), entre otros; comprueban que normalmente la regeneración de Nothofagus pumilio está asociada a eventos catastróficos: algunos en tiempos pasados contemporáneos al hombre y otros mucho más antiguos, por ejemplo las glaciaciones y el volcanismo, así como a perturbaciones de menor escala. La regeneración de la lenga en Aisén ha sido documentada hace un tiempo, por Schlegel et al. (1979) quien comprobó, que la especie es menos tolerante a la sombra como otros Nothofagus, pero presenta regeneración en claros formados por las caídas 
Figura $\mathrm{N}^{\circ} 7$

BOSQUE NATIVO EN MACIZO MONTAÑOSO QUEMADO EN REITERADAS OCASIONES, MÁS DE 40 AÑOS ATRÁS. POR CONSIGUIENTE LA REGENERACIÓN DE LADERAS ES MUY IRREGULAR,

PRINCIPALMENTE CON NOTHOFAGUS PUMILIOY EMBOTHRIUM COCCINEUM. ESTE ÚLTIMO ES UN ÁRBOL PIONERO EN TERRENOS DEGRADADOS

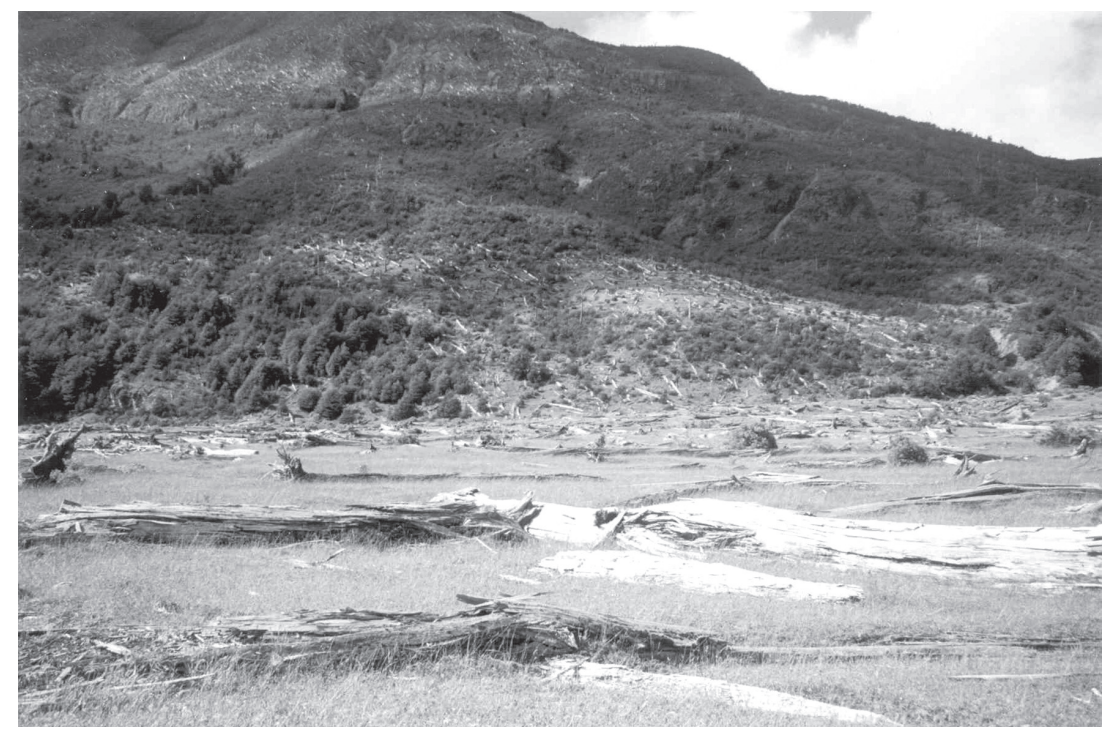

Fuente: Colección personal del autor.

Figura $\mathrm{N}^{\circ} 8$

RECOLONIZACIÓN DE LADERAS QUE PERDIERON EL BOSQUE DE NOTHOFAGUS A CAUSA DE LOS INCENDIOS. POR SU RÁPIDO CRECIMIENTO EL GOBIERNO REGIONAL DE AISÉN PROPICIÓ LAS FORESTACIONES CON PINUS PONDEROSA Y P. CONTORTA.

LOS RODADOS EN ESTOS RELIEVES SON MUY FRECUENTES. EN PRIMER PLANO MODESTOS RENUEVOS DE NOTHOFAGUS PUMILIO Y EMBOTHRIUM COCCINEUM

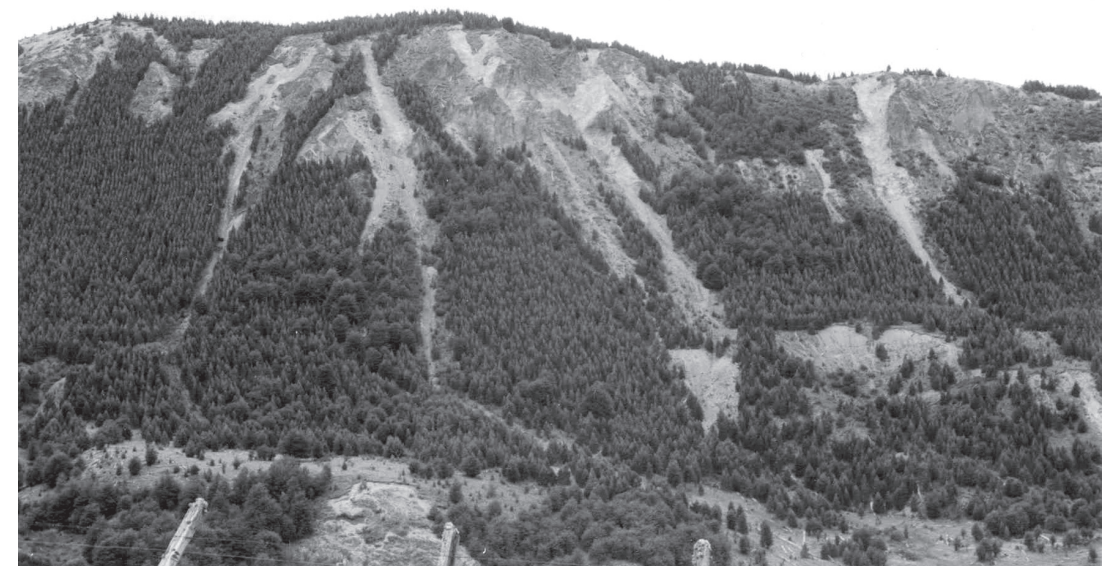

Fuente: Colección personal del autor. 
de árboles. Por lo demás, en la patagonia chilena la estructura de estos bosques es descrita como un mosaico de parches coetáneos de tamaño variable compartiendo espacios por penetraciones de la estepa.

Estos parches coetáneos pueden ser originados también por lo que denominamos perturbaciones a menor escala. Así son frecuentes las caídas masivas de árboles viejos o sobremaduros por la acción del fuerte viento que proviene del este patagónico, o por las acciones de avalanchas y rodados que son muy frecuentes en la región. Abren claros donde las pendientes y las bajas temperaturas son más acentuadas, y en esos sectores la regeneración arbórea posterior, es más reducida. En los conos de detritos dejados por estos procesos, suele producirse una recuperación relativamente lenta. La regeneración de $N$. pumilio en respuesta a perturbaciones es extremadamente variable, dependiendo de las condiciones ecológicas del sitio. En lugares con impacto notorio de herbívoros como ganado y liebres, la regeneración es baja en estos suelos derivados de cenizas volcánicas (Roig et al., 1985).
En este sector de estudio la regeneración de las fagáceas y particularmente de la lenga, es muy deficiente e irregular, a medio siglo de haber sido arrasado por el fuego. Caso más notorio aún es en otra cuenca más grande de la hoya del río Aisén, el denominado valle del Emperador Guillermo (vecino de esta área de estudio), el cual también es objeto de nuestro interés a partir de este primer análisis. Una de las consecuencias de esta lenta regeneración observada por nosotros, se debería a la presencia de numerosos afloramientos rocosos que presentan pendientes superiores a al $35 \%$ y al fuerte avance de la erosión eólica en laderas incluso en suaves pendientes. El efecto de la gravedad en la topografía, el ramoneo del ganado, principalmente bovino, y la influencia de los vientos provenientes de la estepa oriental, particularmente cálidos e intensos en el verano austral; desmantelan la capa orgánica del suelo, y por consiguiente, las posibilidades de regeneración son muy escasas ( $\mathrm{Fi}$ guras $\mathrm{N}^{0} 9$ y $\left.\mathrm{N}^{\circ} 10\right)$.

Otra causa, considerada con frecuencia por los ingenieros forestales y agrónomos de

Figura $\mathrm{N}^{\circ} 9$

DEGRADACIÓN E INTENTOS DE PROTECCIÓN DEL HÁBITAT RURAL EN LA CUENCA DEL ESTERO

RICHARDS VESTIGIOS DE ANTIGUOS INCENDIOS EN EL MACIZO MONTAÑOSO Y EN LA MEDIA

LADERA. LA PRADERA ARTIFICIAL GENERADA EN LA TERRAZA, COBIJA UNA CASA PROTEGIDA POR

UNA CORTINA DE ÁRBOLES CONTRA EL VIENTO. BORDE DE LA TERRAZA EROSIONADA, Y PRESENCIA DE RENUEVOS PRINCIPALMENTE DE NOTHOFAGUS

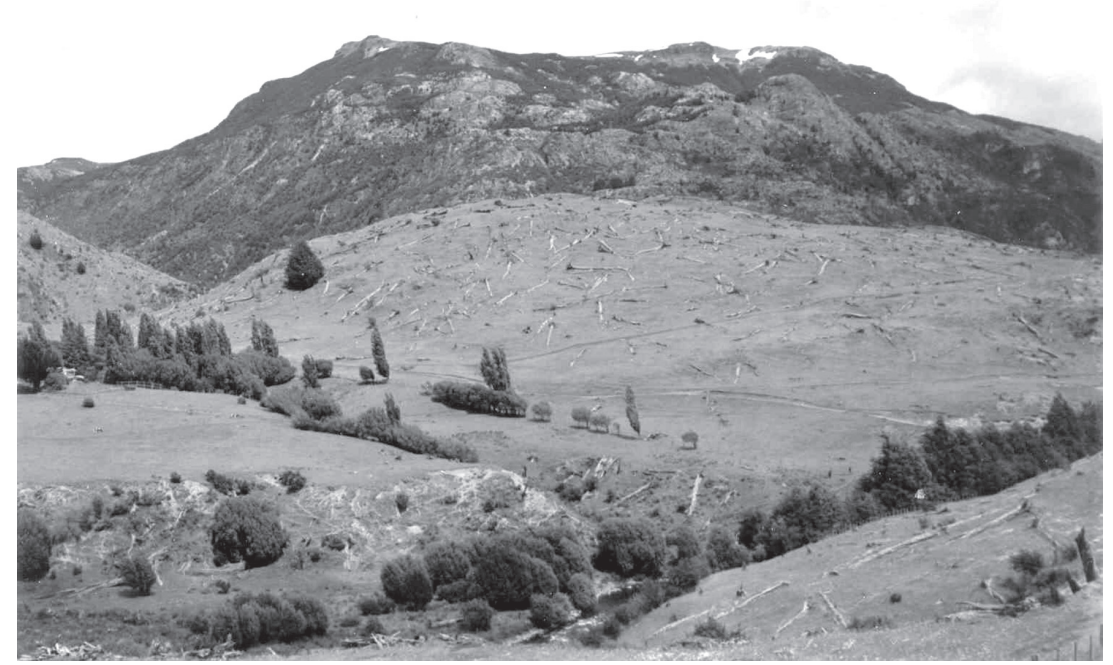

Fuente: Colección personal del autor. 
PÉRDIDA IRREVERSIBLE DEL BOSQUE DE NOTHOFAGUS PUMILIO EL CUAL ES REEMPLAZADO POR UNA PRADERA QUE PRESENTA ADEMÁS PROCESOS EROSIVOS DE DIFERENTES GRADOS, PONIENDO EN GRAVE PELIGRO EL DESARROLLO DE LOS ESCASOS RENUEVOS ARBÓREOS EN LA CIMA DE LA COLINA

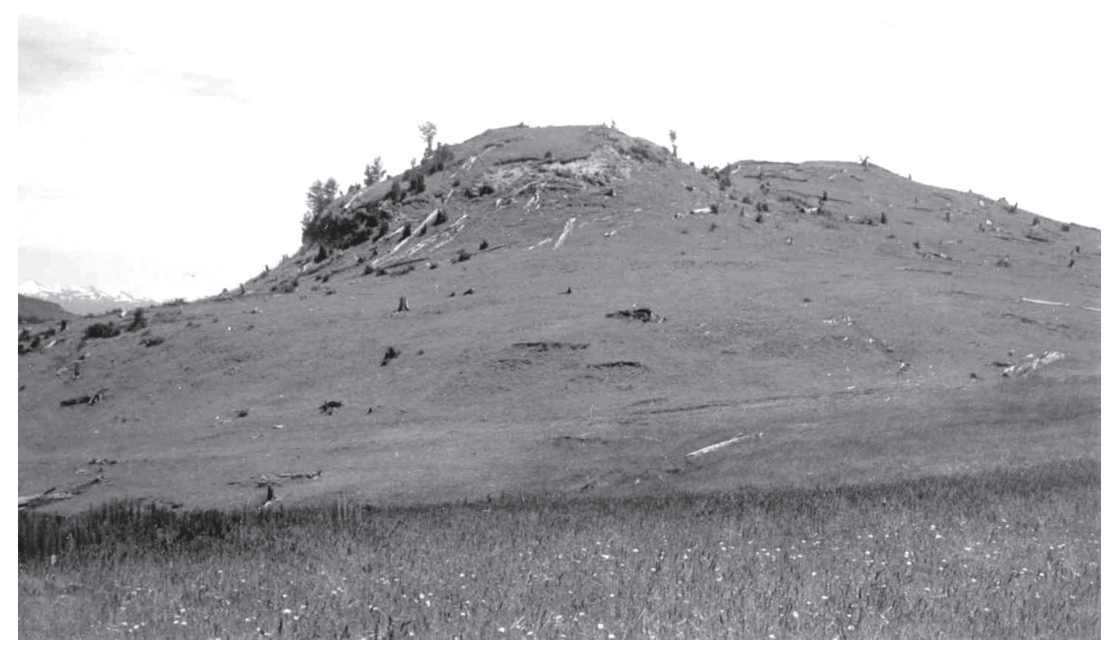

Fuente: Colección personal del autor.

Aisén de la pobre regeneración del bosque nativo quemado, cuyo espacio hoy día está en gran parte cubierto por pastizales, algunas plantaciones de pinos y un cementerio de troncos caídos; se debe a la pobre semiIlación que dejó aquí el bosque de Nothofagus pumilio, pues no habrían quedado árboles madres capaces de generar semillas al desaparecer ante los reiterados fuegos.

Ya Mascareño en 1987 comprobó que este Nothofagus posee máximos de abundancia de semillas, calculando que en estas latitudes tendrían lugar a intervalos cada 6 a 8 años. Esta disminución de semillas en relación con la lenta regeneración de este bosque, estaría también complementada en nuestra área de estudio, por la presencia de un sustrato superficial bastante delgado y desmantelado, debido a los efectos del viento y del ramoneo de herbívoros; lo cual incidiría en la reducción de su capacidad germinativa y reproductiva.

Por otra parte, puede asociarse a esta situación, lo que postula Premoli (2004) en cuanto a que los suelos de N. pumilio en la zona patagónica, son pobres en nitrógeno debido a la mineralización lenta de la hojarasca y la elevada acidez. Aparte, desde el punto de vista adaptativo, según Stern \& Roche (citado en Donoso et al., 2004) puede ocurrir que las poblaciones ubicadas hacia los extremos ecológicos de distribución en las poblaciones marginales de una especie se caracterizan por estar sometidas a altas intensidades de selección. Esto podría suceder con comunidades en el límite altitudinal superior del bosque de lenga, donde serían seleccionados aquellos individuos adaptados a las bajas temperaturas, a la sequía fisiológica derivada de estas, a las fuertes pendientes, al congelamiento del suelo y a la limitada duración de la estación de crecimiento. La disminución por la altura en el número de semillas, la viabilidad de estas y su capacidad germinativa, según Donoso (2004), resultarían en una reducción en la potencialidad reproductiva de los bosques de lenga.

En la patagonia, el efecto de la relación latitud-altitud influye notoriamente en la morfología de los individuos de N. pumilio. En nuestra área de estudio constatamos, que esto no es una excepción. 
Otro indicio de degradación de la vegetación prístina aquí, es la presencia cada vez más predominante de especies introducidas como: Lupinus polyphyllus (chocho) que invade las praderas, del Cytisus monspessulanus (retamo) arbusto colonizador de hasta $5 \mathrm{~m}$ de alto, de formas variadas e irregulares que es común en orillas de caminos, y de la Rosa rubiginosa (rosa mosqueta) particularmente en sectores más áridos.

\section{Consideraciones finales}

Las consecuencias de grandes incendios en Aisén entre 1926 y 1952, concentrados sobre todo en bosques de Nothofagus; han afectado a las cuencas hídricas y suelos de esta región austral; y por lo cual el gobierno regional ha impulsado la forestación con coníferas extranjeras en las cuencas más afectadas.

Los efectos principales de esta perturbación antrópica están representadas por notorios procesos erosivos que se observan a menudo próximos a los caminos, con efectos lamentables sobre las cuencas, cuyos cursos de agua reciben grandes volúmenes de sedimentos generando inundaciones, y obstruyendo incluso los desagües de los ríos a los fiordos de Chile austral. Además son frecuentes también en la región los deslizamientos naturales y avalanchas en áreas de bosques no intervenidos, y ello se incrementa desastrosamente con la intervención humana, por ejemplo con la explotación de leña de lenga. Otro antecedente evidente de las alteraciones de estos ecosistemas boreales patagónicos, es el impacto que ha traído la construcción desde 1983 de la denominada Carretera Austral de Chile, destinada a construir más de $700 \mathrm{~km}$ de caminos, para sacar del aislamiento a los habitantes australes de estas áreas inhóspitas del país.

Es urgente poner bajo manejo las áreas privadas de bosques y controlar la explotación maderera de la foresta todavía no intervenida. Debe consignarse que la CONAF ha llevado a cabo desde hace aproximadamente unos 20 años, algunos planes de forestación con pinos extranjeros y manejo con lenga en la zona, y que han tenido éxito en los sectores de rápido crecimiento de este árbol.
Sin embargo, se ha encontrado un área de considerable superficie donde la regeneración del bosque de Nothofagus después de transcurrido unos 5 decenios de los grandes fuegos, a diferencia de otros sectores quemados, es muy lenta e incluso en algunos lugares es casi nula. El bosque original en esta cuenca del estero Richards correspondía a la asociación Nothofagus pumilioNothofagus dombeyi "Lenga-Coigüe de Magallanes", podría haber ocupado franjas inferiores a Lenga y que en la actualidad están siendo forestadas con Pino ponderosa y Pino contorta, como un plan de manejo iniciado recientemente por organismos estatales (INFOR, CONAF, Gobierno Regional) para recuperar estos terrenos actualmente en gran parte desnudos. Existen ciertos vestigios de esta asociación que no fueron alcanzadas por lo siniestros, en el fondo de algunas quebradas de esta subcuenca.

Los censos florísticos realizados nos demostraron que en aquellos lugares donde hay pastoreo, la recuperación de la lenga (N. pumilio) se desarrolla lentamente, acompañada en los sectores de laderas por el notro (E. coccineum), y de un cortejo florístico de hierbas que iría en aumento.

Otra constatación interesante es observar la importante presencia de plantas exóticas naturalizadas en estos bosques andino-patagónicos, lo cual en el área de estudio no es una excepción particularmente, porque son invasoras de bosques de Nothofagus. Esto, entre otros efectos, tiene incidencia sobre el espectro biológico nativo y constituyen indicadores del grado de perturbación de estas comunidades.

Dada entonces la lenta recuperación del bosque original, al observar por ejemplo el tamaño delgado del fuste de los renuevos, particularmente en sectores de laderas (en las cuales son muy comunes los deslizamientos y rodados) para proteger los suelos, INFOR y CONAF han llevado a cabo un plan de reforestación con pinos extranjeros en la hoya del río Aisén desde 1984. El mayor incremento de plantación fue con Pino ponderosa a partir de 1991. Durante el año 2004 se plantaron 3.595 ha de coníferas exóticas, de las cuales un $87 \%$ correspondía a Pino ponderosa, un $3,3 \%$ a Pino oregón y 
un $2 \%$ a Pino contorta. El $7,4 \%$ restante corresponde a plantaciones mixtas (Moreno y Obando, 2007).

El tema presentado es un primer avance para introducirnos tal vez en una curiosidad geobotánica para procurar descifrar los por qué de esta escasa regeneración de un bosque; en una región en la cual después de varios decenios de acaecidos los grandes fuegos en muchas de las áreas afectadas existe, al menos algo, de regeneración del bosque nordpatagónico.

Probablemente, las especies con amplias distribuciones geográficas poseen características genéticas complejas, particularmente en el caso de Nothofagus pumilio, árbol de amplio rango de distribución latitudinal y altitudinal en Chile.

Actualmente CONAF y el Gobierno Regional están incorporando sitios como estos al SNASPE, a objeto de implementar medidas de manejo adecuadas dentro de una Plan de Ordenación Forestal, para impulsar la recuperación de bosques autóctonos.

\section{Agradecimientos}

Se agradece al SAG-Aisén (Unidad de Recursos Naturales), INFOR, DGA-MOP y a CONAF (Depto. Manejo de Fuego) por la información proporcionada.

\section{Referencias bibliográficas}

ALFARO, O. Estudio de crecimiento en lenga (Nothofagus pumilio Poepp et Endl.Krasser) en las masas forestales más importantes de la XIa Región Aisén. Memoria de título. Valdivia: UACH, Fac. Cs. Forestales, 1982.

ARMESTO, J.; SMITH, C.; RAMÍREZ, P.; LEÓN, A. y ARROYO, M. Biodiversidad y conservación del bosque templado en Chile. Revista Ambiente y Desarrollo, 1992, № 8, p. 19-24.

ARMESTO, J.; P.; LEÓN-LOBOS, A. y M. ARROYO. Los bosques templados del sur de Chile y Argentina: Una Isla Biogeográfica. En: VILLAGRÁN, C.; ARROYO, M. y ARMES-
TO, J. (Eds.). Ecología de los bosques nativos de Chile. Santiago de Chile: Ed. Universitaria, 1995, p. 23-28.

BORGEL, R. Geomorfología. Vol. II. Colección Geografía de Chile. Santiago de Chile: Instituto Geográfico Militar, 1982.

BRAUN-BLANQUET, J. Fitosociología. Bases para el estudio de las comunidades vegetales. Madrid: Editorial Blume, 1979.

BRION, C.; GRIGERA, D.; PUNTIERI, J. y RAPOPORT, E. Plantas exóticas en bosques de Nothofagus. Comparaciones preliminares entre el norte de la patagonia y Tierra del Fuego. Monografías Academia Nacional de Ciencias Exactas, Físicas y Naturales, 1989, $N^{\circ} 4$, p. 37-48.

CABRERA, A. Regiones Fitogeográficas argentinas. Enciclopedia Argentina Agricultura y Jardinería II. Buenos Aires: ACME, 1976.

CABRERA, A. y WILLINK A. Biogeografía de América Latina. Serie Biología, monografía $N^{\circ}$ 13. Ciudad de México: OEA,1973.

CASTELLANOS, A. y PÉREZ-MOREAU, R. Los tipos de vegetación de la República Argentina. Monografías Insituto de Estudios Geogrráficos, 1944, № 4, p. 1-154.

CONAF. Consideraciones generales respecto los incendios forestales en Aisén. Informe técnico. Cohaique: Departamento del Fuego de XI Región, 2006.

DGA-MOP. Datos meteorológicos de la XI Región. Santiago de Chile: Dirección General de Aguas-Ministerio de Obras Públicas, 2007.

DI CASTRI, F. Esquisse écologique du Chili. En: DELAMARE-DEBOUTEVILLE, C. et RAPOPPORT, E. (Eds.). Biologie de I'Amerique Australe. Paris: CNRS, 1968, Vol. IV.

DIMITRI, J. La región de los bosques andino patagónicos. Sinopsis general. Buenos Aires: Colección Científica. INTA, 1972.

DONOSO, C. Bosques templados de Chile y Argentina. Variación, estructura y di- 
námica, $4^{a}$ Ed. Santiago de Chile: Editorial Universitaria, 1998.

DONOSO, C.; PREMOLI, A. y GALLO, L. Variación intraespecífica en las especies arbóreas de los bosques templados de Chile y Argentina. Santiago de Chile: Editorial Universitaria, 2004.

GAJARDO, R. La vegetación natural de Chile. Clasificación y distribución geográfica. Santiago de Chile: CONAF-Editorial Universitaria, 1994.

GROSSE, A. Expedición a la Patagonia. Santiago de Chile: Ministerio Obras Públicas, 1979.

HUECK, K. Die Wälder Südamerikas. G.F. Verlag. Stuttgart: Mit eine karte, 1966.

INIA. Mapa Agroclimático de Chile. Santiago de Chile: Instituto Investigaciones Agropecuarias, 1989.

IREN-CORFO. Caracterización climática. Perspectivas de desarrollo de los recursos de la región de Aisén, General Carlos Ibáñez del Campo. Santiago de Chile: IREN-CORFO, 1979 .

MASCAREÑ̃, A. Evaluación de ensayos de semillación y regeneración de lenga (Nothofagus pumilio (Poepp. Endl.) Krasser bajo diferentes tratamientos a la cama de semillas en la reserva forestal Trapananda. Coyhaique: XI Región. Memoria Valdivia. Fac. Cs. Forestales, 1987.

MORENO, P. y OBANDO, M. Pino ponderosa en Aisén. Biometría y genética. Santiago de Chile: INFOR, 2006.

OBERDORFER, E. Pflanzensoziologische Studien in Chile. Ein Vergleich mit Europe. Stuttgart: Flora et Vegetatio. J. Cramer, 1960.

PISANO, E. Esquema de clasificación de las comunidades vegetales de Chile. En: CORFO. Geografía Económica de Chile. Santiago de Chile: CORFO, 1965, Vol. 1.

PISANO, E. Fitogeografía de Fuego Patagonia chilena. Comunidades vegetales. Anales Instituto de la Patagonia III, 1977.
PREMOLI, A. Variación de Nothofagus pumilio (Poepp. et Ende) Krasser. En: DONOSO, C.; PREMOLI, A. y GALLO, L., Variación intraespecífica en las especies arbóreas de Chile y Argentina. Santiago de Chile: Editorial Universitaria, 2004.

QUINTANILLA, V. Biogeografía de Chile. Vol. III. Colección Geografía de Chile. Santiago de Chile: Instituto Geográfico Militar, 1983.

QUINTANILLA, V. Fitogeografía y cartografía vegetal de Chile Austral. Revista Contribuciones Científicas, Área Geociencias, $1989, \mathrm{~N}^{\circ} 87$, p. 5-27.

QUINTANILLA, V. Degradación del bosque nordpatagónico en la cuenca superior del río Palena. Chile meridional ( $\left.43^{\circ} \mathrm{S}\right)$. Revista Geographicalia, 2005, No 47, p. 47-68.

ROIG, F. A. La vegetación de la Patagonia. En: CORREA, M. Flora Patagónica. Buenos Aires: INTA, 1998, Tomo VIII, Vol. 1.

ROIG, F.; ANCHORENA, J.; DOLLENZ, O.; FAGII, A. y MÉNDEZ, E. Las comunidades vegetales de la transecta botánica de la Patagonia austral. En: BOELCKE, O.; MOORE, D. y ROIG, F. Transecta Botánica de la Patagonia Austral Buenos Aires. Buenos Aires: CONICET, 1985.

SAG. Guías de condición para los pastizales de la Ecoregión Templada intermedia de Aysén. Aysén: SAG-Gobierno Regional de Aisén, 1999a.

SAG. Guía descriptiva de los sitios misceláneos para la conservación y de menor valor forrajero de la Región de Aisén. Aisén: Departamento Protección de Recursos Naturales Renovables, 1999b.

SCHLEGEL, F.; VEBLEN, T. y ESCOBAR, R. Estudio ecológico de la estructura, composición y semillación del bosque de lenga (Nothofagus pumilio) XI Región. Valdivia: UACH Serie Técnica Facultad Ingeniería Forestal, 1979.

SCHMITHÜSEN, J. Die räumliche Ordnung der chilenischen vegetation. Bonner Geogr. Abhandlungen, 1956, № 17, p. 1-86. 
Chile, perturbada por grandes fuegos acaecidos 50 años atrás $\left(44^{\circ}-45^{\circ}\right.$ S)

SORIANO, A. Los distritos florísticos de la Patagonia. Revista Investigaciones Agropecuarias, $1956, \mathrm{~N}^{\circ} 10$, p. 323-347.

UNESCO. Classification internationale et cartographie de la végetation. Carte de I'Amérique du Sud au 5.000.000. Paris: UNESCO, 1973.

VEBLEN, T.; VEBLEN, A. \& SCHLEGEL, F. Understorey patterns in mixed evregreen-deciduos Nothofagus forest in Chile. Journal of Ecology, 1979, No 67, p. 809-823.
VEBLEN, T \& SCHLEGEL, F. Reseña ecológica de los bosques de Chile. Bosque, 1982, Año 4, No 2, p. 73-115.

VEBLEN, T.; KITZBERGER, T.; BURNS, B. y REBERTUS, A. Perturbaciones y dinámica de regeneración en bosques del sur de Chile y Argentina. En: VILLAGRÁN, C.; ARROYO, M. y ARMESTO, J. (Eds.). Ecología de los bosques nativos de Chile. Santiago de Chile: Ed. Universitaria, 1995, p. 169-198. 
